\title{
Art School of the Krasnoyarsk Region: Formation Features Analysis Through the Prism of the Fractal Concept
}

\author{
Liliya R. Stroj, Evgeniya S. Tsareva, \\ Mariya M. Chikhachyova, Anastasiya P. Grishhenko* \\ and Andrej Y. Sejbert \\ Dmitri Hvorostovsky Siberian State Academy of Arts \\ Krasnoyarsk, Russian Federation
}

Received 10.10.2021, received in revised form 10.12.2021, accepted 18.01.2022

\begin{abstract}
The article is based on a study aimed to the possibility of applying the fractal concept for the region's artistic life study and the formation of its professional art education system. There are main features of the application of the fractal concept in this study, its subject is the activity of creative leaders at the initial stage of the formation of the professional art education system in Krasnoyarsk at the turn of the XIX-XX centuries. Historical analysis and historiographic approach for studying the formation of art education makes it possible to determine the key origin points of the regional art school, and due to use of an anthropological approach the role of the individuals in the periphery artistic life reveals, as well as the launch and coordination of self-organizing processes. There were a set of factors which determined the unique appearance of the regional art culture and the features of its educational tradition at the initial stage of the professional art education system formation which were manifested primarily through the activities of creative leaders: M.A. Rutchenko and P. I. Ivanov-Radkevich, who could be called as anthropological fractals. The main directions of their work and artistic and teaching methods made it possible to determine the basic provisions for the development of the culture of the region and important steps towards the historical, geographical and ethnographic self-identification in the culture and art of Krasnoyarsk.
\end{abstract}

Keywords: fractal culture concept, professional art education system, M.A. Rutchenko, P. I. Ivanov-Radkevich, art of Krasnoyarsk.

Acknowledgements: The research was carried out with the financial support of the Russian Foundation for Basic Research, the Government of the Krasnoyarsk Territory, the Krasnoyarsk Regional Science Foundation within the framework of the scientific project «Art Education as the foundation of the artistic life of Siberia» No. 19-412-240002.

Research area: art history.

(C) Siberian Federal University. All rights reserved

* Corresponding author E-mail address: nastugrichshenko@gmail.com 
Citation: Stroj, L.R., Tsareva, E.S., Chikhachyova, M.M., Grishhenko, A.P., Sejbert, A.Y. (2022). Art school of the Krasnoyarsk region: formation features analysis through the prism of the fractal concept. J. Sib. Fed. Univ. Humanit. soc. sci., 15(1), 124-132. DOI: 10.17516/1997-1370-0882

\title{
Художественная школа Красноярского края: анализ особенностей формирования сквозь призму фрактальной концепции
}

\author{
Л.Р. Строй, Е.С. Царева, \\ М.М. Чихачёва, А.П. Грищенко, А.Ю. Сейберт \\ Сибирский государственный институт искусств \\ имени Дмитрия Хворостовского \\ Российская Федерачия, Красноярск
}

\begin{abstract}
Аннотация. Статья посвящена возможностям использования фрактальной концепции для исследования региональной художественной жизни и особенностей формирования академической художественной школы. Предметом исследования является деятельность творческих лидеров на начальном этапе становления системы профессионального художественного образования в Красноярске на рубеже XIX-XX вв. Применение основных положений фрактальной концепции культуры позволило выделить базовые элементы сложения региональной художественной традиции. Исторический анализ и историографический подход к изучению становления художественного образования дает возможность определить ключевые точки происхождения региональной художественной школы, а за счет использования антропологического подхода раскрывается роль индивидов в периферийной художественной жизни. Уникальность региональной художественной культуры и особенности ее образовательной традиции на начальном этапе становления системы профессионального художественного образования определялись комплексом факторов, которые проявлялись, прежде всего, в деятельности творческих лидеров: М.А. Рученко и П.И. ИвановаРадкевича. Главные направления их работы и художественно-педагогические методы позволили выявить основные положения развития культуры региона и важные шаги на пути к исторической, географической и этнографической самоидентификации в культуре и искусстве Красноярского края.
\end{abstract}

Ключевые слова: фрактальная концепция культуры, система профессионального художественного образования, М.А. Рутченко, П.И. Иванов-Радкевич, искусство Красноярска.

Благодарности: Исследование выполнено при финансовой поддержке Российского фонда фундаментальных исследований, Правительства Красноярского края, Красноярского краевого фонда науки в рамках научного проекта «Художественное образование как фундамент художественной жизни Сибири» № 19-412-240002.

Научная специальность: 17.00.09 - теория и история искусства. 


\section{Введение}

Творческий облик культуры определенной региональной традиции формируется под влиянием совокупности факторов (исторических, географических, экономических, социокультурных). Важнейшая роль в формировании художественной традиции и региональной художественной школы принадлежит процессам взаимовлияния событий, определяющих динамику художественной жизни региона и становление системы профессионального художественного образования.

История и состав художественного образования изучались рядом российских и зарубежных авторов, среди которых значимы работы О.В. Стукалова, А.И. Щербакова, Н.Н. Ярошенко, А.П. Бредихина, Л.А. Рапацкой, Л.Г. Медведева, П. Эббса, А. Д. Эфленда и мн. др. Зачастую в исследованиях рассматриваются условия сложения системы художественного образования как в регионе, так и по стране в целом. Вопрос же взаимовлияния художественного процесса и профессионального творческого образования наименее изучен. Частично особенности взаимодействия образовательных и культурных организаций рассматриваются в работах Б.Я. Столярова, Г.С. Трифоновой; образовательные программы учреждений культуры в контексте воспитательной парадигмы подрастающего поколения характеризует Л.Г. Медведев, различные аспекты творческого высшего образования и его влияния на профессиональную судьбу студента затрагивает Н.И. Ануфриева. Вопросы включения параметров этнической среды в программу регионального художественного образования рассматриваются М.И. Долженковой, Т. Я. Шпикаловой, А. Паази. Этапы формирования художественного процесса отдельного города охарактеризовали Г.Е. Гун, Н.Е. Чащина, Ж. А. Мингалева, А. С. Претт, $\Phi$. Бианчинни. В своих работах авторы обосновывают интеллектуальный потенциал вузов как ресурс регионального экономического развития.

Особо можно выделить исследования, направленные на выявление роли челове- ка в культурном процессе. В их основе находится представление о «человеческом капитале» (Zubanova, Betextin, 2018) или «кадровом потенциале» (Borovskix, 2019). Корреляция традиций художественного образования и региональной художественной школы рассматривается с позиции включения в образовательный процесс предметов по местному фольклору или специфическим видам искусств (Sushkova, 2019; Grashhenko, 2020; Vakulenko, 2014).

Отраслевое образование (как необходимая часть творческой жизни) воспитывает «культурную элиту», влияющую на формирование как художественной школы, так и культурного контекста региона в целом. Анализ основных механизмов взаимовлияния художественного образования и культуры региона актуален, так как позволяет проследить этапы становления «художественной школы» и, соответственно, выявить закономерности ее развития во времени. Особое значение для запуска и непосредственного развития системных процессов художественной жизни регионов (в сравнении с метрополиями) приобретает инициативная деятельность творческих лидеров.

Использование антропологического подхода в сочетании с фрактальной концепцией позволяет установить основные факторы и предпосылки, на базе которых произошло сложение той или иной региональной художественной школы, в том числе и ее специфического языка творческого самовыражения.

Уже на начальном этапе формирования системы профессионального художественного образования региона закладывается совокупность факторов, определяющих неповторимый облик региональной художественной культуры и особенности ее образовательной традиции, что проявляется, прежде всего, через деятельность творческих лидеров («антропологических фракталов»). Творческий метод региональной художественной школы и компоненты художественного языка ее творцов во многом зависят от принципов образовательно- 
го процесса, заложенных ее основателями на начальном этапе.

В данном исследовании объектом изучения являются процессы взаимовлияния художественного образования и художественной жизни региона сквозь призму фрактальной концепции (на примере Красноярского края). Предмет исследования - деятельность творческих лидеров на начальном этапе сложения системы профессионального художественного образования Красноярья (рубеж XIX-XX столетий).

\section{Методы}

В исследовании представлена апробация нового методологического подхода - фрактальной концепции (по Б. Мандельброту). Ее актуальность продиктована необходимостью подчеркнуть особый антропологический акцент региональной художественной жизни, а также стремлением единовременного сочетания в исследовании диахронического и синхронического анализа, процессуального и структурного аспектов.

Встречающееся в научной литературе понятие «культурный фрактал», по определению австралийского учёного П. Даунтона, отражает «конфигурации всех существенных характеристик его культуры» (Nikolaeva, 2017). Фрактальная концепция изучения культуры строится на определении фрактала Б. Мандельброта и основана на самоподобии всех его частей, где каждый отдельный участок является отражением целого или его большей части в общей иерархии сферы культуры. Культурный процесс мыслится как система фрактальных комплексов, каждый из которых в различных аспектах повторяет целое, т. е. культуру страны в целом. Соответственно, каждая региональная школа будет выстраиваться по алгоритму, повторяющему сложение культуры в стране в целом и своим функционированием отражать основные процессы в художественной жизни страны. Это подчеркивает исследователь Е.В. Николаева, говоря о локальных культурных фракталах как о «частных случаях единой формулы культуры человечества» (Nikolaeva, 2017).

Таким образом, региональный художественный процесс может быть рассмотрен как расширение влияния ведущего культурного центра (в случае с Российской империей - Санкт-Петербурга и Москвы) на различные губернии посредством «носителей традиции», т. е. конкретных людейфракталов. Человек служит первоосновой, атомом социокультурной мультиструктуры, которую он формирует по принципам самоподобия, генерируя и реализуя свои идеи. Соответственно, в основе фрактальной концепции в исследовании социокультурных процессов лежит антропологический подход.

Фрактальная концепция помогает представить систему академических художественных традиций как пространственновременную модель, где человек (носитель академических художественных традиций) является фракталом, социальные связи и отношения интерпретируются как фрактальные цепочки, культурная диффузия (благодаря которой происходит расширение ареала функционирования общеевропейской академической культурной модели) выступает фрактальным процессом, синхронный срез локальной художественной жизни - паттерном, региональная художественная система (культура, где базовые элементы «откристаллизованы», сформированы, функционируют и способны к самовоспроизводству) - мультифракталом.

Привлечение антропологического подхода в исследовании раскрывает роль личности в формировании художественной жизни периферии, запуске и координации самоорганизационных процессов. Апробация фрактального подхода в сфере искусствознания, в частности музыкального краеведения, представлена в работах М.Н. Дрожжиной и Е. С. Царевой.

Творческие личности становятся системообразующими центрами художественного процесса, который во многом осуществляется благодаря рекурсивным процедурам множества алгоритмов по сохранению, развитию и воспроизводству тра- 
диций (Tsareva, Drozhzhina, 2020). При этом следует отметить, что каждый новый фрактал отличается от предыдущего - происходит определенная эволюция, направленная в конечном итоге на порождение собственного фрактала - кусочка культурной жизни: благодаря возможности профессионального обучения кадров культуры и искусства в регионе начинает формироваться свой культурный центр. Таким образом, точкой отсчета появления региональной художественной школы становится открытие и развитие первых учебных заведений.

Исторический анализ и историографический подход для изучения становления художественного образования в регионе дают возможность определить ключевые точки зарождения региональной школы.

Для определения основных особенностей регионального художественного языка обоснованно применяются методы семиотического и философско-искусствоведческого анализа произведений искусства. На основе полученных данных выделяются основные направления развития образовательного процесса, обусловленные региональными особенностями и их влиянием на следующее поколение творцов. Отдельно отметим, что в исследовании экстраполируются в сферу художественного краеведения некоторые выводы теории диалога как главного механизма межкультурного взаимодействия (по Ю.М. Лотману) и методологические подходы к феномену «памяти культуры» (Я. Ассман, П. Нора, Ю. Лотман, М. Бахтин) в сопряжении с принципами регионального анализа.

\section{Обсуждение}

Важную роль на начальном этапе формирования красноярской художественной школы (рубеж XIX-XX веков) ${ }^{1}$ играли про-

\footnotetext{
В 1822 г. в Енисейскую губернию вошли пять округов (бывших уездов): Енисейский (в него вошла территория упраздненного Туруханского уезда под названием Туруханского комиссарства, позже отдельного управления), Красноярский, Канский (из частей Красноярского, Енисейского уездов, Иланской и Бирюсинской волостей Нижнеудинского уезда Иркутской губернии от Бирюсы до Кана), Минусинский (из южной части Красноярского уезда) и Ачинский (из западной части Красноярского,
}

цессы самоорганизации художественных процессов - в качестве новой формы социальных отношений для региона выступили культурно-просветительские общества (пр. «Общество любителей музыки и литературы», г. Красноярск, осн. в 1886 г.). Изначально деятельность непрофессиональных просветительских обществ компенсировала отсутствие объектов инфраструктуры в области искусства и профессиональных академических кадров в регионе. Благодаря работе музыкальных и художественных обществ в городе появились базисные компоненты складывающейся системы академических традиций - организовывались исполнительские коллективы (оркестры, ансамбли, светские хоры), проводились выставки.

Именно стратегические инициативы творческих обществ (как результат потребности саморазвития) легли в основу организации профессионального художественного образования Красноярска, а именно организация рисовальных классов (1910 г.) и народной консерватории (1920 г.).

Однако конструктивных результатов самоорганизационных культурных движений не произошло бы без направляющей и структурирующей роли творческих лидеров - грамотных специалистов, координирующих социальную энергию. Творческие лидеры (изначально, как правило, «внешние»), попавшие в город различными путями, формировали культурный генофонд Красноярья.

Исходя из теории фрактальной концепции культуры, в центре каждого регионального культурного центра находятся определенные ключевые единицы - антропологические фракталы, стоящие у истоков формирования художественной школы. Для Красноярья (Енисейской губернии) такими творческими лидерами стали: в области художественного образования - М. А. Рутченко (чья деятельность предшествовала осно-

юго-запада Енисейского и северо-востока Томского уездов). Административным центром вновь образованной губернии был утвержден город Красноярск. Подобное административно-территориальное деление сохранялось до начала 1920-х гг 
ванию Красноярской рисовальной школы) и его последователи - художники А.С. Шестаков и Д.И. Каратанов (Stroj, 2020); в области музыкального образования - основатель Красноярской народной консерватории П. И. Иванов-Радкевич (Stroj, Tsareva, 2021).

Выпускник Киевской рисовальной школы Н.И. Мурашко Михаил Александрович Рутченко (1863-1937) прибыл в Красноярск в 1889 г. и активно включился в тогда еще только начинающуюся историю развития художественного образования Енисейской губернии: преподавал рисование в мужской и женской гимназиях, а в 1891 г. стал основным преподавателем в первых воскресных рисовальных классах. Через год, благодаря знакомству с городской элитой, у Рутченко появилась возможность показать населению работы своих воспитанников на первой документально зафиксированной художественной выставке Красноярска. В 1893 г. Рутченко открыл в Красноярске первую иконописную мастерскую, а обратившись в Академию художеств, получил поддержку рисовальной школы в виде учебных пособий и образовательной программы. Несмотря на тот факт, что М.А. Рутченко работал в Красноярске всего до 1895 г., его деятельность предопределила условия эффективного развития художественных процессов: экспозиционной культуры, художественной критики, общественно-творческой деятельности, мастерового сектора, просветительской работы, художественного образования (Stroj, 2020).

Наиболее важным вкладом М.А. Рутченко в художественный процесс региона стало воспитание двух выдающихся мастеров: Л.А. Чернышева и Д.И. Каратанова. В 1892 г., получив начальное художественное образование в классах Рутченко, они уехали учиться: Чернышев в Московское училище живописи, ваяния и зодчества (отделение архитектуры), Каратанов в СанктПетербургскую Императорскую Академию художеств. Вернувшись в Красноярск, оба художника стали выдающимися мастерами и продолжателями академических традиций в Красноярске.
В 1895 г. Рутченко уехал из Красноярска. Его дело продолжили ученики его школы - Дмитрий Иннокентьевич Каратанов и Леонид Александрович Чернышев, которым учитель передал мечту об открытии в Красноярске рисовальных классов. В 1905 г. красноярские мастера Д. Каратанов, А. Шестаков, М. Костылев, Г. Козлов, П. Владимиров уведомили Енисейское губернское управление о создании первого городского товарищества художников. В этом же году были открыты классы рисования и живописи, которые из-за проблем материально-финансового характера прекратили свою работу в 1907 г. Однако активность красноярских художников позволила вновь поднять вопрос о возможности учреждения в Красноярске рисовальной школы на заседании Красноярской городской управы в 1909 г. В итоге было принято положительное решение: открытие Красноярской рисовальной школы состоялось 27 января 1910 г.

В основе творческого метода как М.А. Рутченко, так и его учеников лежали традиции русской академической живописи, на базе которых строилась система художественного образования. Продолжая подход В.И. Сурикова, М.А Рутченко поддерживал в учениках интерес к этнографии и особенностям культуры коренных народов Сибири и Хакасии. Мастер приветствовал проявление в работах своих учеников «местных особенностей», как географических и исторических, так и культурных. Следует отметить большое влияние творческого метода В.И. Сурикова на сложение региональной школы - важную роль сыграли этнографические экспедиции, ставшие традицией со времен его работы над полотнами «Покорение Сибири Ермаком», «Взятие снежного городка» и незавершенной композиции «Княгиня Ольга встречает тело Игоря». Скрупулезное изучение самобытности региона послужит точкой опоры для включения в художественное творчество этнографической тематики и народного творчества. Особый сплав региональных культурных особенностей и русской реалистической школы становится той самой от- 
правной точкой, на которой вырастет художественная школа Красноярского края.

В сфере музыкального образования в Енисейской губернии «антропологическим фракталом» рубежа XIX-XX вв. стал П.И. Иванов-Радкевич (Stroj, Tsareva, 2021). Павел Иосифович Иванов-Радкевич музыкант-исполнитель (пианист и скрипач), светский хормейстер и регент, дирижер, композитор, самый популярный в Красноярске частный педагог и преподаватель музыкальных дисциплин во многих городских учебных учреждениях.

Павел Иосифович окончил в Петербурге Императорскую придворную певческую капеллу и приехал в Красноярск в 1897 г. Он был самым популярным частным педагогом по фортепиано, общее число учениковпианистов за годы, проведенные им в Красноярске, достигало 50 человек. В числе значимых результатов педагогической деятельности Павла Иосифовича - создание смешанного хора (более 60 человек) из учеников женской гимназии и учительской семинарии, который также был открыт для просвещённых любителей из «взрослых посторонних». Он принимал участие во многих концертах и постановках сцен из опер в Красноярске («Жизнь за царя» М. Глинки, «Мазепа» П. Чайковского, «Аида» Дж. Верди и др.). Некоторые из юных хористов П.И. Иванова-Ракевича в будущем составили мировую музыкальную элиту: М. Сладковский, П. Словцов, М. Токаревич (одна из «музыкальных звездочек» женской гимназии, стала солисткой Миланской оперы). П.И. Иванов-Радкевич был руководителем первого в Красноярске симфонического оркестра. Он активно развивал и культуру исполнительского мастерства, и содействовал развитию «культуры слушателей».

Его многолетнее активное самосовершенствование по означенным выше векторам творческой деятельности вылилось в создание объемного музыкальнотеатрального сочинения - детской оперы «Царевна Земляничка». Основой ее либретто стала пьеса-сказка в стихах П. С. Аллегро-Соловьевой. В этом произведении и его постановках гармонично соеди- нились все таланты автора - педагога, дирижера, композитора, организатора. Опера создавалась П.И. Ивановым-Радкевичем в течение 1914 года, в последующие несколько лет ее клавир только редактировался и шла работа над оркестровкой. К исполнению вокальных ролей были привлечены ученицы автора в женской гимназии и некоторые взрослые красноярские любители. Изначально опера была сочинена в сопровождении фортепиано. Как вспоминает сын композитора А.П. Иванов-Радкевич, «красноярцы ждали свою оперу, своих артистов», и «Царевну Земляничку» местная публика сразу встретила с интересом. Премьерные показы оперы проходили в стенах гимназии, но уже в конце 1915 г. состоялось первое представление «Царевны Землянички» на сцене Городского театра им. Пушкина. Оно прошло под аккомпанемент автора на рояле, имело большой успех.

Активная деятельность Павла Иосифовича привела к открытию в 1920 г. Народной консерватории.

Влияние творческих лидеров на развитие художественного процесса Красноярья неоспоримо. М. А. Рутченко и П. И. ИвановРадкевич воспитали плеяду новых кадров, развивали творческую среду и способствовали формированию г. Красноярска как культурного центра. Развитие образовательных и художественных традиций, заложенных мастерами, на протяжении $\mathrm{XX}$ столетия привело к самоопределению отдельной региональной школы.

Важно отметить, что М.А. Рутченко и П.И. Иванов-Радкевич не только заложили основу системы профессионального художественного образования региона, но в своей педагогической деятельности предопределили основные методологические подходы, повлиявшие на формирование так называемых маркеров регионального творчества. К последним можно отнести: цитирование произведений искусства коренных народов, практическое соотнесение художественного артефакта с этнографическими особенностями региона (культурными, климатическими, географическими и социальными маркерами территории), 
отражение истории и мифологии коренных народов.

\section{Выводы}

Анализ исторического развития художественного процесса Красноярского края сквозь призму фрактальной концепции позволяет сделать выводы о ключевой роли творческих лидеров в формировании образовательных и художественных традиций региона (в их взаимообусловленности), что впоследствии приводит к самоопределению самостоятельной художественной школы.

Рассмотрение начального этапа сложения системы профессионального художественного образования Красноярья (рубеж XIX-XX столетий) в опоре на фрактальный подход позволяет выявить ряд ее региональных особенностей:

- Ведущая роль «антропологических фракталов» (творческих лидеров) в развитии региональной культуры.

- Важное значение процессов самоорганизации в образовательной деятельности сферы художественной культуры.

- Изначальная нацеленность региональной художественной культуры на воспроизводство академической художественной модели через образовательную деятельность. В основе творческого метода находились академические тради- ции, на которые постепенно накладывались региональные маркеры. Если первые педагоги получали свое образование «в центре», то каждое новое поколение учеников впитывало академическую школу с все более нарастающим «региональным элементом».

- Стремление к воспроизведению, трансляции и рефлексии.

- Направленность к историкогеографической и этнографической самоидентификации в искусстве («сибирская идентичность»).

Таким образом, применение фрактального подхода к исследованию регионального художественного процесса позволяет высветить как его основные закономерности, так и обнаружить предпосылки зарождения новых элементов региональной художественной школы в ее непрерывном развитии.

Осмысление основных механизмов взаимодействия художественного образования и художественного процесса, а также роли творческих лидеров современной культуры позволит более точно спрогнозировать сценарий культурного развития страны и ее отдельных субъектов, что представляется особенно актуальным в условиях реализации национальных проектов «Культура» и «Образование» в Российской Федерации.

\section{Список литературы / References}

Borovskix, N. V., Kipervar, E. A. (2019). Sistema professional'nogo obrazovaniya kak faktor razvitiya kadrovogo potenciala: regional'ny'j aspect [The vocational education system as a factor in the development of human resources: a regional aspect], In Omskij nauchny'j vestnik. Seriya «Obshhestvo. Istoriya. Sovremennost» [Omsk Scientific Bulletin. Series «Society. History. Modernity»], 1, 71-78.

Vakulenko, E. G. (2004). Regionalnaya sistema professionalnogo obrazovaniya v sfere narodnogo dekorativno-prikladnogo iskusstva [Regional system of vocational education in the field of folk arts and crafts]. Krasnodar, Krasnodar State University of Culture and Arts, 40 p.

Grashhenko, A. G., Sushkova, L. N. (2020). Sovremennye problemy muzykalnoj etnopedagogiki [Contemporary problems of musical ethnopedagogy], In Nauka. Kul'tura. Iskusstvo: aktual'ny'e problemy' teorii i praktiki [The science. Culture. Art: Actual Problems of Theory and Practice], 170-174.

Zhukov, D. S., Lyaminб S. K. (2007). Metafory' fraktalov v obshhestvenno-politicheskom znanii [Metaphors of fractals in socio-political knowledge]. Tambov, Tambov State University named after G. R. Derzhavin, $136 \mathrm{p}$.

Zubanova, L. B., Betextin, A. V., Czukerman, V. S. (2018). Chelovecheskij kapital sfery kultury: aktualnye orientiry formirovaniya kadrovogo potenciala regiona [Human capital in the sphere of culture: cur- 
rent guidelines for the formation of human resources in the region], In Vestnik kul'tury' $i$ iskusstv [Bulletin of culture and arts.], 3 (55), 102-109.

Isopeskul, O. Yu. (2012). Fraktalnaya priroda organizacionnoj kultury [The fractal nature of organizational culture], In Upravlenie ekonomicheskimi sistemami [Management of economic systems], 11 (47), available at: https://cyberleninka.ru/article/n/fraktalnaya-priroda-organizatsionnoy-kultury.

Mandelbrot, B. (2004). Fraktaly, sluchaj i finansy. [Fractals, chance and finance], M, R\&C Dynamics, $255 \mathrm{p}$.

Nikolaeva, E. V. (2016). Koncepciya fraktalnosti v postneklassicheskoj filosofii kultury [The concept of fractality in post-non-classical philosophy of culture], In Filosofiya i kultura [Philosophy and culture], 1 (97), 142-149. DOI: 10.7256/1999-2793.2016.1.17512

Stroj, L.R., Tsareva, E. S. (2020). The Influence of Creative Societies on the Formation of Art Education in Krasnoyarsk of the Late 19th - Early 20th Centuries, In Journal of Siberian Federal University. Humanities \& Social Sciences, 13 (6), 963-971.

Stroj, L.R. (2020). Vklad Mixaila Rutchenko v razvitie xudozhestvennoj zhizni Sibiri XIX veka (na primere Irkutska i Krasnoyarska) [Mikhail Rutchenko's contribution to the development of the artistic life of Siberia in the 19th century (on the example of Irkutsk and Krasnoyarsk)], In Arte, 2 (1), 14-19.

Sushkova, L. N., Grashhenko A. G., Yakovleva N. F. (2019). E'tnomuzy'kal'noe obrazovanie kak osnova soxraneniya narodnoj kul'tury' regiona (iz opy'ta Belgorodskoj oblasti) [Ethnomusical education as the basis for preserving the folk culture of the region (from the experience of the Belgorod region)], In Sovremenny'e problemy' nauki i obrazovaniya [Modern problems of science and education], 3, 101-101.

Filko, Antonina I., Avdeeva, Yulia N., Kistova, Anastasia V., Pimenova, Natalia N., Robachevskaya, Nina N. (2021). Ethnocultural Dynamics of the Krasnoyarsk Territory in the Works of Krasnoyarsk Artists, In Journal of Siberian Federal University. Humanities \& Social Sciences, 14 (6), 873-889.

Fomin, V. P. (1977). Muzykalnaya zhizn kak problema teoreticheskogo muzykoznaniya [Musical life as a problem of theoretical musicology], Moscow, $22 \mathrm{p}$.

Tsareva, E.S., Drozhzhina M.N. (2019). Fraktal'ny'j podxod k analizu sistemy' regional'noj akademicheskoj muzy'kal'noj tradicii [Fractal approach to the analysis of the system of the regional academic musical tradition], In Vestnik muzy'kal'noj nauki [Musical Science Bulletin], 26, 167-180.

Tsareva, E.S. (2014). Muzy'kal'naya zhizn' Krasnoyarska ot istokov do 1922 goda: puti formirovaniya muzy'kal'noj kul'tury' evropejskogo tipa [Musical life of Krasnoyarsk from its origins to 1922: ways of forming a musical culture of the European type], Krasnoyarsk State Institute of Arts, Krasnoyarsk, 368 p. 